\title{
Percepção da comunidade nipo-brasileira residente em Curitiba sobre o cadastro de medula óssea
}

\author{
The perception of bone marrow registry of the Brazilian Japanese descendants living in the city of \\ Curitiba, Brazil
}

\author{
Alexandra M. Watanabe \\ Claudete A. Omotto ${ }^{2}$ \\ Leonardo Di Colli
}

Viviane M. H. Hayashi ${ }^{4}$

\begin{abstract}
O transplante de medula óssea é uma terapia de escolha utilizada para o tratamento de doenças hematológicas. Entrementes, a probabilidade de se encontrarem doadores compatíveis na população em geral é relativamente baixa. Felizmente, há uma maior probabilidade de se encontrar um doador compativel em doadores de grupos étnicos semelhantes aos do paciente. Especificamente quanto aos nipo-brasileiros, existem poucos virtuais doadores cadastrados no Hemepar de Curitiba. Frente a essa situação, este estudo teve por objetivo conhecer a percepção dos nipo-brasileiros residentes em Curitiba sobre o Cadastro Nacional de Doadores de Medula Óssea e as possíveis causas da pequena adesão a este cadastro. O estudo foi realizado com 400 nipobrasileiros, entrevistados aleatoriamente por meio de um questionário semiestruturado, no periodo de abril a junho de 2008. Os resultados foram tabelados pelo Microsoft Office Excel 2003, e as análises estatísticas realizadas pelo Software Statgraphics, versão 5.1. Constatou-se que, mesmo possuindo um bom nivel cultural (56\%) e do bom entendimento sobre a medula óssea (77\%), a baixa adesão apresentada para o cadastramento como potencial doador voluntário, principalmente pelas gerações nissei e sansei, deveu-se ao desconhecimento quanto aos locais onde se realizam os cadastros e sobre o processo de doação de medula óssea. Estratégias com vistas a melhorar ainda mais o repasse de informações e esclarecimentos sobre o tema podem ser elaboradas a fim de despertar o interesse e incentivar os potenciais doadores nipobrasileiros residentes em Curitiba a participar do Cadastro Nacional de Doadores de Medula Óssea. Conhecer as características dos diferentes grupos étnicos que compõem a população brasileira é um indicador que poderá ser utilizado no processo de captação de doadores de medula óssea. Rev. Bras. Hematol. Hemoter. 2010;32(2):136-140.
\end{abstract}

Palavras-chave: Grupos étnicos; transplante de medula óssea; cadastro.

\section{Introdução}

O transplante de medula óssea é uma terapia especial utilizada para tratar pacientes com doenças hematológicas e algumas alterações genéticas, para os quais outras alterna- tivas terapêuticas foram consideradas e excluídas. ${ }^{1}$ Envolve a eliminação dos sistemas hematopoético e imunológico de um indivíduo através da quimioterapia e/ou irradiação e subseqüente substituição por células-tronco de outro indivíduo ou do próprio paciente. ${ }^{2}$ Estudos em amostras

\footnotetext{
${ }_{2}^{1}$ Farmacêutica bioquímica do Hemepar - Curitiba-PR.

${ }_{3}^{2}$ Chefe da Enfermagem do Hemonúcleo de Apucarana-PR.

${ }^{3}$ Farmacêutico bioquímico.Diretor do Hemonúcleo de Apucarana-PR.

${ }^{4}$ Enfermeira do Hemepar - Curitiba-PR.
}

Hemepar - Hemocentro Coordenador - Curitiba-PR, e Hemonúcleo de Apucarana-PR

Correspondência: Alexandra Mitiru Watanabe

Rua Deputado Joaquim José Pedrosa, 78, ap.502 - Bairro Cabral

80035-120 - Curitiba-PR - Brasil

Tel.: (55 41) 3253-43-25/9645-21-97

E-mail:amw@onda.com.br/alemwatanabe@hotmail.com

Doi: 10.1590/S1516-84842010005000042 
populacionais demonstram que algumas especificidades HLA características em uma população podem estar ausentes em outras. Antígenos como HLA-A2 e HLA B35 são encontrados em quase todas as populações; já os antígenos HLA-A1, A3, B8 e B 27 são encontrados em caucasoides e negros e raramente em orientais. O HLA A-43 é encontrado quase exclusivamente nos negros, e o HLA-B46 principalmente nos chineses. Existem haplótipos que são característicos de algumas populações: por exemplo, HLA-A1-B8-DR3 em caucasoides, HLA-A2-B35-DR4 em mongois, HLA-A28-B38-DR6 em negros africanos ${ }^{3}$ e HLA-A*33B e 44DRB1*13 nos orientais. ${ }^{1,4}$

O conhecimento da frequência haplotípica HLA por etnia tem papel relevante na procura por um doador compatível. Quando não se encontra dentro da família (25\%), a probabilidade de um paciente encontrar um doador potencial na população em geral é de 1:100.000 (Instituto Nacional do Câncer (Inca). Redome. [Online]. Disponível em http:// www.inca.gov.br). Entretanto, a procura deste doador realizada dentro do grupo étnico do paciente aumentará a chance de se encontrar um doador compatível. ${ }^{1}$ Para isso, é imprescindível que os potenciais doadores estejam inseridos no Cadastro Nacional de Medula Óssea, no Registro Nacional de Doadores - Redome, o que trará maior esperança a um paciente em fila de espera para um transplante.

Bicalho e cols verificaram que, em 1.600 doadores voluntários de medula óssea cadastrados no Hemepar, em Curitiba, 73,9\% se autodefiniram como caucasoides e somente $0,81 \%$ como orientais. ${ }^{1}$

Esse estudo teve por objetivo conhecer a percepção da comunidade nipo-brasileira de Curitiba sobre o Cadastro Nacional de Doadores de Medula Óssea e as possíveis causas da pequena adesão para o cadastro como potenciais doadores.

\section{Material e Método}

Trata-se de uma pesquisa qualiquantitativa, onde um questionário do tipo semiestruturado, contendo 19 questões foi aplicado na forma de entrevista no período de abril a junho de 2008 a 400 pessoas, nipo-brasileiras, após Termo de Consentimento Livre e Esclarecido (TCLE). Foram entrevistadas diversas gerações de nipo-descendentes, desde o issei até o mestiço, com idade entre 18 a 55 anos, residentes em Curitiba. As entrevistas foram realizadas por duas participantes do projeto e por alguns voluntários, previamente treinados. O estudo piloto teve início com os familiares das participantes e frequentadores do Mercado Municipal de Curitiba.

Optou-se por entrevistar nipo-brasileiros relacionados aos familiares dos entrevistadores e amigos pertencentes a grupos sociais e educativos como Nikkey (Associação Cultural e Beneficente Nipo-Brasileira de Curitiba), Celin (Centro de Línguas e Interculturalidade da UFPR), Cenibrac (Casa do Estudante Nipo-Brasileiro de Curitiba), ABD (Associação Brasileira de Dekasseguis), Apaex (Associação
Paranaense de Ex-Bolsistas Brasil-Japão) após obtenção de autorização para as entrevistas em cada uma dessas instituições citadas. A coleta de dados foi aleatória.

As variáveis analisadas foram: idade, sexo, grau de escolaridade, naturalidade, estado civil, caracterização étnica (issei, nissei, sansei, yonsei, mestiço), ser frequentador de comunidade nipo-brasileira, ser doador de sangue. Outras variáveis analisadas referem-se ao conhecimento do entrevistado sobre medula óssea; sobre o procedimento para se cadastrar; sobre as campanhas para cadastramento; a doação de medula óssea propriamente dita; a doação voluntária; inscrição em cadastro; familiares cadastrados; pessoas do grupo de convívio do entrevistado que tenham feito transplante de medula óssea; compatibilização em grupos étnicos semelhantes e a adesão ou não do entrevistado no cadastro.

Com a finalização da aplicação dos questionários, iniciou-se a alimentação do banco de dados para análise estatística. Os resultados foram tabelados pelo Microsoft Office Excel 2003 e as análises estatísticas realizadas pelo Software Statgraphics, versão 5.1.

Esta pesquisa foi aprovada pelo Comitê de Ética em Pesquisa da Secretaria de Estado da Saúde do Paraná - Sesa, em 24/04/2008, processo no ${ }^{\circ}$ 2/2008.

\section{Resultados}

A distribuição dos entrevistados em relação ao sexo, escolaridade e geração está descrita abaixo.

A maior parte dos entrevistados pertencia ao sexo feminino $(58,4 \%)$; os solteiros $(50,7 \%)$ predominaram em relação aos casados (45,5\%). Quanto à escolaridade, predominou o terceiro grau completo $(56,0 \%)$, seguida daqueles que ainda não o concluíram - universitários $(28,0 \%)$ e do primeiro e segundo graus completos $(12,0 \%)$.

Em relação à geração dos entrevistados, $53 \%$ se incluíram no grupo de sansei, seguido de nissei $(25,3 \%)$, de mestiços (12,5\%), yonsei 7,3\%, e issei ou nativo 1,5\%.

Quanto à naturalidade, aproximadamente $36,0 \%$ são de Curitiba e Região Metropolitana; 41,0\% nasceram em outras cidades do estado do Paraná, 14,0\% em São Paulo, 9,0\% são de outros estados e $1,0 \%$ é nativo do Japão.

Cerca de $25,7 \%$ dos entrevistados frequentam duas ou mais comunidades, tais como a religiosa e a esportiva; $20,0 \%$ pertencem à comunidade cultural ou social ou esportiva (Clube Nikkey) ou religiosa (Seicho-no-Ie, Budismo), porém, $54,2 \%$ dos entrevistados responderam que não frequentam nenhum grupo social específico de cultura japonesa.

Quando questionado se já estava cadastrado como doador de medula óssea, $90 \%$ dos entrevistados responderam "não". A estes, foi perguntado quais os prováveis motivos de ainda não participar do Cadastro (Tabela 1). A pergunta consistia de sete alternativas, podendo-se escolher uma ou mais. Com base nas respostas, $12,8 \%$ dos entrevistados disseram desconhecer que existem serviços que 
Tabela 1. Motivos do não cadastramento dos entrevistados da comunidade nipo-brasileira de Curitiba (abril a junho de 2008) $(n=358)$

\begin{tabular}{lcc}
\hline Variável & No $^{\circ}$ & $\%$ \\
\hline Desconhecimento referente ao cadastro & 46 & 12,8 \\
Desinteresse pela doação & 25 & 6,9 \\
Medo & 23 & 6,4 \\
Desconhecimento do processo de doação & 80 & 22,3 \\
Preconceito & 0 & 0 \\
Sensação de perda de parte do organismo & 0 & 0 \\
Outros & 74 & 20,4 \\
Duas ou mais respostas & 109 & 30,7 \\
Não respondeu & 01 & 0,3 \\
\hline Total & 358 & -100 \\
\hline
\end{tabular}

Tabela 2. Motivos do não cadastramento dos entrevistadoscom mais de uma resposta, da comunidade nipo-brasileira de Curitiba (abril a junho de 2008)

\begin{tabular}{lc}
\hline Variável & Respostas \\
\hline Desconhecimento referente ao cadastro & 72 \\
Desinteresse pela doação & 28 \\
Medo & 49 \\
Desconhecimento do processo de doação & 89 \\
Preconceito & 2 \\
Sensação de perda de parte do organismo & 15 \\
Outros & 11 \\
\hline
\end{tabular}

Tabela 3. Conhecimento da comunidade nipo-brasileira de Curitiba sobre as campanhas de doação de medula óssea, por geração (abril a junho 2008) $(n=400)$

\begin{tabular}{|c|c|c|c|c|c|}
\hline $\begin{array}{c}\text { Geração } \\
\text { nipo-brasileira }\end{array}$ & sim & $\%$ & não & $\%$ & $\begin{array}{c}\text { Não } \\
\text { respondeu }\end{array}$ \\
\hline Issei & 01 & 0,6 & 05 & 2,14 & 00 \\
\hline Nissei & 35 & 21,3 & 66 & 28,2 & 00 \\
\hline Sansei & 88 & 53,6 & 124 & 52,5 & 01 \\
\hline Yonsei & 14 & 8,5 & 15 & 6,41 & 00 \\
\hline Mestiço & 26 & 15,2 & 24 & 10,2 & 01 \\
\hline Não identificado & 01 & 0,6 & 01 & 0,43 & 00 \\
\hline Total & 164 & 100 & 234 & 100 & 02 \\
\hline
\end{tabular}

fazem o cadastramento e $22,8 \%$ referiram desconhecer as etapas desde o cadastro inicial até a doação propriamente dita. Nunca se interessaram por esta questão foi a resposta de $6,9 \%$ dos entrevistados, sendo o medo o motivo para $6,4 \%$ dos mesmos.

Os motivos mais frequentes daqueles que optaram por mais de uma resposta são mostrados na Tabela 2.

Sobre as campanhas de doação de medula, $58,5 \%$ dos entrevistados declararam não ter conhecimento sobre o tema. Destes, 28,2 \% são nissei, 52,5\% sansei, 6,41\% yonsei e 10,2\% são mestiços (Tabela 3). Dos 164 entrevistados que disseram ter conhecimento de campanhas sobre a medula óssea, aproximadamente $35 \%$ disseram ter recebido alguma informação pela TV e $31 \%$ por outros meios de divulgação, como campanhas em escolas, faculdades, empresas, serviços de hemoterapia, secretarias de saúde municipais, prefeituras, seguido pela distribuição de folders, conforme mostra a Tabela 4. Além disso, 17\% dos entrevistados disseram ter percebido alguma informação em mais de um veículo de comunicação.

Tabela 4. Meios de divulgação citados pela comunidade nipo-brasileira de Curitiba como forma de conhecimento sobre o tema. Período: abril a junho de $2008(n=164)$

\begin{tabular}{lcc}
\hline Meio de divulgação & N & $\%$ \\
\hline Jornal & 02 & 1,2 \\
TV & 58 & 35,4 \\
Rádio & 01 & 0,6 \\
Folders & 14 & 8,5 \\
Familiares do Receptor & 08 & 4,9 \\
Mais de um veículo de comunicação & 28 & 17,0 \\
Outros (faculdades, escolas, campanhas) & 51 & 31,1 \\
Não responderam & 02 & 1,2 \\
\hline Total & 164 & 100 \\
\hline
\end{tabular}

Quanto à compreensão sobre a medula óssea, a maioria $(77,7 \%)$ declarou possuí-la. Sobre o procedimento do transplante de medula óssea, $78 \%$ dos entrevistados declararam não ter conhecimento e aproximadamente $59 \%$ disseram desconhecer o fato de haver maior chance de encontrar um doador dentro de um mesmo grupo étnico.

Em relação ao conhecimento sobre familiares serem cadastrados como doador, 56,0 \% responderam "não" e 29,5\% não tinham esta informação.

Dos 38 mestiços $(9,5 \%)$ que não estavam cadastrados como doador de medula óssea no momento da pesquisa, 25 $(68,4 \%)$ mostraram-se favoráveis ao cadastramento. Por outro lado, quanto à possibilidade de se cadastrar, $50 \%$ dos issei se mostraram indecisos, seguidos pelos nissei (46\%), sansei (45,1\%), mestiço (34,2\%) e yonsei (32\%) (Tabela 5).

\section{Discussão}

Segundo dados do IBGE, 2000, o Brasil possui 1.405.685 $(0,8 \%)$ de nipo-brasileiros. No estado do Paraná, a população estimada é de 140 mil, sendo 50 mil residentes em Curitiba (Instituto Brasileiro de Geografia e Estatística (IBGE). [Online]. Disponível em ftp://ftp.ibge.gov.br/Censos/Censo_ Demografico_2000/Indicadores_Sociais/UFs/).

O Brasil caracteriza-se por ser um país multirracial. No início do século XX, diversos grupos étnicos saíram de seus países de origem e emigraram para o Brasil em busca de melhores condições de vida. O mesmo aconteceu com o povo japonês, que, em 1908, saiu do seu país em meio à crise econômica e social com a esperança de dias melhores no 
Tabela 5. Distribuição dos entrevistados em relação aos não cadastrados favoráveis ao cadastramento e indecisos da comunidade nipo-brasileira de Curitiba, no período de abril a junho de $2008 \quad(n=400)$

\begin{tabular}{ccccccccc}
\hline Variáveis & \multicolumn{2}{c}{ Entrevistados } & \multicolumn{2}{c}{ Não cadastrados } & \multicolumn{2}{c}{$\begin{array}{l}\text { Favoráveis ao } \\
\text { cadastramento }\end{array}$} & \multicolumn{2}{c}{ Indecisos } \\
\hline Faixa etaria & $\mathrm{N}$ & $\%$ & $\mathrm{~N}$ & $\%$ & $\mathrm{~N}$ & $\%$ & $\mathrm{~N}$ & $\%$ \\
$<20$ & 40 & 10,0 & 32 & 8,8 & 18 & 53,3 & 10 & 31,3 \\
$20-29$ & 126 & 31,5 & 119 & 33,0 & 57 & 47,9 & 54 & 45,4 \\
$30-39$ & 78 & 19,5 & 73 & 20,2 & 35 & 47,9 & 31 & 42,5 \\
$40-49$ & 110 & 27,5 & 100 & 27,7 & 48 & 48,0 & 46 & 46,0 \\
$50-55$ & 44 & 11,0 & 34 & 9,4 & 14 & 41,2 & 15 & 44,2 \\
Não clas. & 02 & 0,5 & 02 & 0,5 & 01 & 50,0 & 00 & 0,0 \\
Geração & & & & & & & & \\
Mestiço & 50 & 12,5 & 38 & 9,5 & 25 & 68,4 & 13 & 34,2 \\
Yonsei & 29 & 7,2 & 25 & 6,3 & 12 & 48,0 & 8,0 & 32,0 \\
Sansei & 212 & 53,0 & 193 & 48,3 & 90 & 46,6 & 87 & 45,1 \\
Nissei & 101 & 25,3 & 98 & 24,4 & 43 & 43,9 & 45,0 & 45,9 \\
Issei & 06 & 1,5 & 06 & 1,5 & 3 & 50,0 & 03 & 50,0 \\
Não clas. & 02 & 0,5 & 00 & 0,0 & 00 & 00 & 00 & 00 \\
\hline
\end{tabular}

outro lado do mundo. O navio Kasato Maru trouxe ao Brasil ${ }^{5}$ os primeiros imigrantes japoneses junto com suas tradições, costumes e caracteres genéticos. Porém, devido às diferenças entre o Oriente e o Ocidente, além do choque cultural, o preconceito racial fez com que estes imigrantes se organizassem e vivessem em pequenas colônias, na tentativa de preservar seus costumes, com o sonho de retornar ao seu país de origem. ${ }^{6}$ Os casamentos eram permitidos apenas entre os descendentes de japoneses. Por descendente entendem-se os filhos nascidos no Brasil (nissei ou segunda geração) cujos pais são nativos ou issei; sansei (neto de japoneses ou terceira geração), yonsei (bisneto de japoneses ou quarta geração). ${ }^{7,8}$ No presente estudo, filhos de pais de gerações diferentes foram considerados como sendo o da geração seguinte da mais longínqua. Assim, se um dos pais é nissei $\left(2^{\mathrm{a}}\right)$ e o outro sansei $\left(3^{\mathrm{a}}\right)$, o filho será yonsei $\left(4^{\mathrm{a}}\right)$. A partir da década de 70 , o número de casamentos interétnicos começou a aumentar. ${ }^{5,9}$ Porém, em Curitiba, no grupo pesquisado ainda prevaleceram os casamentos entre descendentes da $2^{\mathrm{a}}, 3^{\mathrm{a}}$ e $4^{\mathrm{a}}$ gerações $(85 \%)$ e apenas $12 \%$ de casamentos foram entre nipo-brasileiros e não descendentes. Esta característica demonstra a procura pela identidade étnica e cultural, que também se expressa na participação em associações e clubes culturais ${ }^{10}$ onde predominam os associados nipo-brasileiros, porém aberto à comunidade em geral. Juntos, dividem ideais comuns, princípios básicos e compartilham costumes semelhantes. ${ }^{8}$ Assim, entrevistar nipo-brasileiros em locais onde há reunião dos mesmos mostrou ser bastante eficiente. Essa estratégia de entrevista foi também adotada com êxito nos estudos etnográficos entre brasileiros nikkey ${ }^{11}$ e na comunidade japonesa na Grande Vitória? ${ }^{7}$

$\mathrm{O}$ perfil dos nipo-brasileiros residentes em Curitiba mostrou que, aproximadamente, metade dos entrevistados pertence a algum tipo de comunidade nipônica, seja de lazer, religioso ou esportivo. Entretanto, apesar do caráter gregário do povo japonês, ${ }^{12} \mathrm{o}$ viver em colônias ou frequentar associações não predominou no grupo pesquisado, o que mostra sua maior integração na comunidade local, em um processo de aculturação descrito por Kajita e colaboradores. ${ }^{13}$

A maioria $\left(59,0 \%\right.$ ) dos entrevistados possui o $3^{\circ}$ grau completo, caracterizando a valorização do desenvolvimento intelectual que o issei trouxe do Japão, incentivando os filhos na ascensão profissional e social ${ }^{14}$ que lhes permitisse também visibilidade social. ${ }^{15}$ Além disso, $28 \%$ dos entrevistados são estudantes universitários, sendo originários de diferentes locais tanto do Paraná quanto de outros estados.

As campanhas sobre doação de medula óssea atingiram a população em estudo através da TV, pois $35,4 \%$ dos entrevistados afirmaram ter conhecimento sobre o assunto por divulgação veiculada pela televisão, e $17 \%$ através de mais de um veículo de comunicação. Entretanto, o teste $\chi^{2}$ mostrou diferença estatisticamente significativa $(p<0,05)$ entre $o$ conhecimento sobre as campanhas de doação de medula óssea e a geração nipo-descendente (Tabela 3 ). A $3^{\text {a }}$ geração (sansei) e a $2^{\mathrm{a}}$ geração (nissei) mostraram-se mais conscientes sobre as campanhas de doação de medula óssea do que os mestiços e os yonsei.

Quando questionado sobre o motivo pelo qual ainda não estava cadastrado como doador, 22,3\% (Tabela 1) que optaram por apenas uma resposta afirmaram não conhecer $o$ processo da doação e suas consequências. De 109 entrevistados que escolheram mais de uma resposta, 89 referiram desconhecer o processo de doação. Além disso, percebeuse o conhecimento equivocado sobre o assunto. A pergunta mais frequente dos entrevistados era se a medula era retirada da espinha dorsal. 
Destaca-se que as gerações de nissei $(45,9 \%)$ e de sansei $(45,1 \%)$ mostraram-se as mais indecisas em se cadastrar como doador voluntário. Por outro lado, os yonsei (48\%) e os mestiços $(68,4 \%)$ foram mais receptivos à idéia em participar do Cadastro.

\section{Conclusão}

Pelos resultados obtidos por esta pesquisa, observouse a necessidade de provocar um "despertar" na comunidade nipo-brasileira de Curitiba para a temática doação de medula óssea e desenvolver estratégias de esclarecimento para o grupo de indecisos, enfatizando a importância da sua participação.

Pesquisas relacionadas ao HLA dos nipo-brasileiros podem ser realizadas para melhor desenvolvimento do tema abordado. O conhecimento das características culturais dos diferentes grupos étnicos que compõem a população brasileira poderá trazer maior efetividade aos serviços de hemoterapia na captação dos doadores para a doação de sangue bem como para o cadastramento dos potenciais doadores de medula óssea.

\section{Abstract}

Bone marrow transplantation is the therapy of choice for some hematological diseases. However, in the general population there are few compatible donors for patients. Fortunately, there is a better chance of finding compatible donors in the same ethnical group as the patient. In the city of Curitiba, the state of Paraná, few Japanese descendants are registered as bone marrow donors in the State Blood Center (Hemepar). The purpose of this study was to investigate the perception of the Japanese descendants of the Bone Marrow Registry and in particular the possible reasons that few of these individuals are registered. Data were collected from April to May of 2008, through an interview process applied at random to 400 Japanese descendants. Results were tabulated on a Microsoft Office Excel 2003 spreadsheet and statistical analyses were performed using the Statgraphics software, version 5.1. In spite of the good cultural background (56\%) and good knowledge about bone marrow (77\%), Japanese descendents in particular second and third generation subjects did not join the registry not only because of the lack of information about where it is possible to be registered but also because of the lack of information about the donation process itself. It is necessary to develop strategies to provide correct information to the population in order to stimulate Japanese descendants to join the bone marrow registry. Knowledge of the characteristics of the different ethnical groups which compose the Brazilian population is an indicator that may help to increase the number of registered bone marrow donors. Rev. Bras. Hematol. Hemoter. 2010;32(2):136-140.

Key words: Ethnic groups; bone marrow transplantation; census.

\section{Agradecimentos}

À Comunidade nipo-brasileira de Curitiba, ao José Lúcio dos Santos, ex-diretor do Hemocentro Coordenador, à Susana Helena Gai Mercer, diretora do Hemocentro Coordenador - Curitiba; à Anália Maria Breckenfeld Machado, chefe da Divisão de Produção do Hemepar, Curitiba e ao Departamento de Imunogenética e Genética da UFPR.

\section{Referências Bibliográficas}

1. Bicalho MG, Ruiz TM, da Costa SMC, Zacarias FR. Haplótipos HLA mais freqüentes em doadores voluntários de medula óssea de Curitiba, Paraná. Rev Bras Hematol Hemoter. 2002;24(4):1.

2. Hoffbrand AV, Peth JE, Moss P. Fundamentos em hematologia. $4^{\mathrm{a}}$ ed. Porto Alegre: Artmed; 2004.

3. Zago MA, Falcão RP, Pasquini R. Hematologia - fundamentos e prática. São Paulo: Atheneu; 2004.

4. Ruiz TM, Costa SMCM, Ribas F, Luz PR, Lima SS, Bicalho MG. Human leucocyte antigen allelic groups and haplotypes in a brazilian sample of volunteer donors for bone marrow transplant in Curitiba, Paraná, Brazil. Transplant Proc. 2005;37:2293-96.

5. Saito H. A presença japonesa no Brasil. São Paulo: T.A. Queiroz/ Edusp; 1980. (Coleção Coroa Vermelha: Estudos Brasileiros I).

6. Sano RK. Japoneses: sonhos e pesadelos. Campinas: Fundo de Assistência à Cultura, 1989. Disponível em http://www.terrabrasileira. net/folclore/influenc/japonhis.html. Acesso em: 20 janeiro 2009.

7. Suda JR, Souza L. Identidade social em movimento: a comunidade japonesa na Grande Vitória (ES). Psicol Soc. 2006;18(2):72-80.

8. Zagonel RM, Carvalho MG. Influência da cultura de origem dos descendentes de imigrantes japoneses no desempenho acadêmico e no concurso vestibular/2000 da UFPR. Curitiba. Tuiuti: Ciência e Cultura 2006;38:19-42.

9. Lesser J. A negociação da identidade nacional: imigrantes, minorias e a luta pela etnicidade no Brasil. São Paulo: Unesp. 2001.

10. Ikari LT. Lazer do imigrante japonês no Brasil. In: Estudos japoneses. $1^{\mathrm{a} e d . ~ S a ̃ o P a u l o: ~ F F L C H / U S P ; ~ n º 25, ~ 2005 . ~ p .71-80 . ~}$

11. Hoga LAK, Lima VM, Alcântara AC. Envolvimento masculino em saúde reprodutiva: estudo etnográfico entre brasileiros nikkeys. Acta Pal Enf 2000 13; nº especial, parte II, p. 201-204.

12. Ennes MA. Ocupação, renda e origem étnica: um estudo de caso. Caderno pós-ciências sociais - São Luís 2005;2(3):86.

13. Kajita GT, Gomes MHA, Diniz DHMP, Saito T, Kai I, Schor N. Processo de aculturação, estado civil e estrutura familiar em nipobrasileiros de primeira e segunda geração. VIII Encontro Latino Americano de Pós-Graduação; 2008, São José dos Campos, São Paulo. (Anais de Congresso)

14. Deliberador LMY. A influência da cultura japonesa no comportamento dos nisseis da geração de cinqüenta e sessenta anos e seu engajamento no trabalho voluntário. IX Congresso Brasileiro de Ciências da Comunicação da Região Sul; 2008 29-31 maio, Guarapuava, Paraná.

15. Woortmann EF. Japoneses no Brasil / brasileiros no Japão: tradição e modernidade. Rev Antropol. 1995;38(2):7-37.

Avaliação: Editor e dois revisores externos

Conflito de interesse: sem conflito de interesse

Recebido: 09/08/2009

Aceito após modificações: 04/11/2009 